\title{
ANÁlise da IDEAÇÃo, AVALIATIVIDADE E TEMATIZAÇÃo EM NARRATIVAS DE APRENDIZAGEM DE LÍNGUAS ${ }^{1}$
}

\section{(Analysis of ideation, appraisal, and information flow in language learning histories)}

\author{
Adail Sebastião Rodrigues-JÚNIOR \\ (Universidade Federal de Ouro Preto - UFOP)
}

\begin{abstract}
Over the last few years, Language Learning Histories have revealed aspects of foreign language acquisition processes that neither ordinary observation nor emic research has been able to capture. This is true because the multiple aspects of the learning language system are not easily perceived by observation techniques only, especially those related to students' awareness of the process they are part of. Language Learning Histories have much to say about students' feelings, wishes, and standpoints, and these histories have undoubtedly struck a chord with foreign language students and the field experiences they have had worldwide. The importance of Language Learning Histories to Second/Foreign Language Acquisition Research has motivated me to understand it as a genre with typical as well as distinct discursive features, when compared to the narratives Labov (1972) investigated. This paper thus aims to analyze Language Learning Histories from a genre-based perspective, by using Systemic-Functional Linguistics genre theory to pinpoint some functional stages that usually appear in the Language Learning Histories studied. The data are thirty seven transcripts of Language Learning Histories from Brazilian students available at AMFALE Project homepage. Following Halliday $\mathcal{E}$ Hasan's (1985) position that every context is in the text, this ongoing research adopts Martin E Rose's (2003) textual approach to both categorize the Language Learning Histories and depict a major picture of this specific genre. The results have demonstrated that a distinguishing feature of this genre, which pervades most of the data analyzed, is the fact that Language Learning Histories present discursive differences in their conclusion, or Coda, in relation to Labov's categorization.
\end{abstract}

Key-words: Systemic-Functional Linguistics; Genre; Language Learning Histories.

1. Esta pesquisa foi apresentada no V Simpósio Internacional de Gêneros Textuais (V SIGET), que ocorreu na Universidade de Caxias do Sul, em Caxias do Sul, RS, no período de 11 a 14 de agosto de 2009, com o apoio da Fundação de Amparo à Pesquisa do Estado de Minas Gerais (FAPEMIG).

D.E.L.T.A., 26:2, 2010 (255-288) 
Resumo: Nos últimos anos, narrativas de aprendizagem de línguas têm revelado alguns aspectos do processo de aquisiz̧ão de língua estrangeira que nem a observação comum ou a pesquisa êmica tem sido capaz de demonstrar. Isso porque os múltiplos aspectos do sistema de aprendizagem de línguas não são apreendidos exclusivamente por técnicas de observação, sobretudo aquelas que se limitam a investigar a concepção que os aprendizes têm acerca do processo do qual eles fazem parte. Narrativas de aprendizagem de línguas têm muito a dizer sobre os sentimentos, desejos e pontos de vista dos aprendizes, além do que, essas narrativas expressam informações que são, de certo modo, parecidas com as experiências de aprendizes de línguas do mundo todo. A importância das narrativas de aprendizagem de línguas para a Pesquisa em Aquisição de Segunda Lingua motivou-me a compreendê-las como um gênero com traços discursivos típicos e, ao mesmo tempo, distintos, quando comparadas às narrativas investigadas por Labov (1972). Este artigo, pois, pretende analisar as narrativas de aprendizagem de línguas a partir de uma perspectiva de gêneros do discurso, usando, para tal, a teoria de gênero da Linguística Sistêmico-Funcional, com o objetivo de explicar os estágios funcionais que frequentemente aparecem nas narrativas estudadas. Os dados são compostos por trinta e sete transcrições de narrativas de aprendizagem de línguas de brasileiros disponíveis na bomepage do Projeto AMFALE. Seguindo a posição de Halliday E Hasan (1985) de que todo contexto está no texto, esta pesquisa em andamento adota a abordagem textual de Martin E Rose (2003) para categorizar e, de igual modo, descrever as narrativas de aprendizagem de línguas como um gênero do discurso específico. Os resultados mostraram que uma característica explícita desse gênero, presente na maioria dos dados analisados, é uma diferença discursiva na conclusão, ou Coda, das narrativas observadas, em relação à categorização laboviana.

Palavras-chave: Linguística Sistêmico-Funcional; Gênero do Discurso; Narrativas de Aprendizagem de Línguas.

\section{Por que narrativas de aprendizagem de línguas? ${ }^{2}$}

O interesse por narrativas não é atual. Aristóteles, em seu tratado $A$ Poética (apud Abbott 2008), já pensava nas possíveis definições de partes de uma narrativa, ao afirmar que o tempo e a ordem dos eventos de uma história são basicamente os mesmos das ações e diálogos em tempo real de

2. O termo narrativa de aprendizagem de línguas, tradução, em língua portuguesa, de language learning history, já foi consagrado por linguistas aplicados do Brasil e do exterior que buscam investigar fenômenos de ensino/aprendizagem de línguas tendo como corpus de análise esses tipos de narrativas. A esse respeito, ver o número temático da Revista Brasileira de Linguística Aplicada que trata especificamente do tema pesquisa narrativa (Revista Brasileira de Linguística Aplicada. v. 8, n. 2, 2008, disponível em http://www.letras.ufmg.br/rbla/revista2008_2.html). 
atores em peças teatrais. A representação de eventos da vida real em relatos sequenciados chamou a atenção de pesquisadores do campo das Ciências Humanas, uma vez que um dos traços definidores de uma cultura encontrase nas estruturas das narrativas, dadas as possibilidades de construção de significação dessa cultura também por meio de histórias (Bell 2002).

Essas possibilidades levaram pesquisadores das Humanidades a olharem para as narrativas por um ângulo diferenciado, porque elas funcionavam como um registro linguístico-discursivo de representações das realidades de seus relatores. Greimas (1966), por exemplo, apresentou uma taxonomia de participantes em narrativas que deu origem a discussões e pesquisas inúmeras acerca do papel de personagens, e suas múltiplas formas de representação textual, em narrativas. Esse movimento inaugurou um campo de pesquisa, nos estudos literários, intitulado estilística literária (Propp 1968), que deu seguimento a várias discussões sobre enredo, tempo e espaço da narrativa e, sobretudo, personagens (Montgomery 1993).

Iniciou-se, por assim dizer, a busca pela sistematização das estruturas de narrativas como registros de "realidades de mundo" de seus relatores, levando sociolinguistas (Labov 1972), antropólogos (Heath 1983), analistas do discurso (Gumperz 1982), entre outros, a estabelecerem padrões de análise para os relatos que investigavam, coletados, em grande medida, em trabalhos de campo com comunidades distintas das suas. Deu-se origem, portanto, à "virada narratológica" (narratological turn), cuja preocupação básica foi tentar estabelecer uma definição de narrativa e de suas partes constitutivas.

No campo dos estudos linguísticos, Toolan (2001) propôs seis características que, segundo ele, definem uma narrativa. São elas: (i) um grau de artificialidade fabricada que a distingue de uma conversa espontânea, devido a um trabalho de reconstrução de uma realidade por parte do relator da história; (ii) a possibilidade de pré-fabricação de uma realidade vivida ou ouvida, uma vez que o relator confere à narrativa um nível de interpretação pessoal que pode não corresponder in toto à realidade representada no relato; (iii) narrativas parecem ter uma trajetória, um início, meio e fim, como discutiu Aristóteles em seu tratado $A$ Poética, como elementos "obrigatórios" de um relato; (iv) narrativas requerem um dizente, alguém que conta a história e consequentemente a representa por meio do discurso que produz; (v) narrativas referem-se a fatos desconectados, no tempo e no 
espaço, do momento real de quem conta a história e de quem a ouve ou lê, visto que, se assim não o fosse, não haveria narrativa, ou representação de uma realidade por parte do relator; (vi) narrativas se referem a eventos distantes no tempo e no espaço em comparação com o momento do relato. Dessas características, Toolan (2001) concluiu que uma possível definição de narrativa seria uma sequência não-aleatória de eventos conectados entre si, envolvendo personagens, reais ou imaginárias, de cujas ações é-nos possível construir uma realidade da qual extraímos exemplos de experiências e, portanto, de aprendizado.

A questão da aprendizagem, como posta na definição de Toolan (2001), confere à narrativa uma característica fundamental: a possibilidade de representar eventos que descrevam experiências das quais possamos aprender e, sobretudo, identificar possibilidades de aprendizagem dos envolvidos na história. Essa característica abriu um leque de pesquisas, especialmente na área da Linguística Aplicada e o Ensino de Línguas, que tem como foco de atenção as histórias contadas por aprendizes de línguas acerca de suas experiências de aquisição da língua-alvo. Essas histórias originaram-se, segundo Pavlenko (2007, 2009), de diários de aprendizes de línguas, comuns nas décadas de 1980 e 1990, em que os aprendizes registravam suas experiências. Com a virada narratológica, os diários cederam espaço para as autobiografias e histórias de vida, eventos narrativos que traduziam, por assim dizer, as etapas da aprendizagem e sua complexidade (Clandinin \& Connelly 2000).

À luz dessa assertiva, Bell (2002) esclarece que as narrativas permitem que pesquisadores observem holisticamente as experiências de mundos dos relatores das histórias registradas nas sequências das narrativas. Em outras palavras, Bell (2002) ilustra que narrativas são construções de uma realidade, podendo cumprir o papel de instrumentos de controle social e de ferramentas de ensino. Isso porque, já na década de 1970, Goffman (1974) chamava a atenção para o fato de que um conto ou anedota, por exemplo, constituía-se em um relato da experiência pessoal de quem conta a história, e não em um mero relato descritivo de um evento ocorrido no passado. $\mathrm{O}$ traço de pessoalidade interpretativa, comum em narrativas, aponta para a possibilidade de constituição de sistemas ideológicos e de pontos de vista pessoais de quem narra a história por meio desses registros linguísticos (Simpson 1993).

O campo da Linguística Aplicada tem se preocupado, entre outros temas, em estudar os vários fenômenos de ensino e de aprendizagem de línguas usando narrativas de aprendizes como corpus de investigação. Pavlenko 
(2007) tem se destacado nesse campo de atuação ao enfatizar a inobservância de alguns pesquisadores dessa área no tocante aos métodos de análise desses dados. Segundo Pavlenko (2007), tem sido comum o agrupamento de questões analíticas em relação aos dados gerados de autobiografias e histórias de vida, tais como, gênero social, atitudes dos aprendizes, estratégias de aprendizagem, fatores sociais, entre outros, sem a devida sistematização metodológica dessas questões de modo a formatá-las em dado analisável. Pavlenko (2007) apresenta cinco limitações dessa abordagem, a saber: (i) a falta de uma base teórica para a análise das narrativas; (ii) a ausência de procedimentos estabelecidos para o agrupamento das categorias linguístico-discursivas a serem analisadas; (iii) a ênfase a eventos recorrentes, sem a devida atenção a eventos que não se repetem com frequência; (iv) o foco exclusivo na informação textual, desconsiderando-se os elementos extra-textuais; (v) e, por fim e mais problemático, a desatenção a como os narradores usam a linguagem para interpretar suas experiências de mundo e se posicionarem como agentes de práticas sociais.

Essas críticas não receberam, até onde sei, atenção significativa de pesquisadores brasileiros, fato que abre um flanco metodológico que precisa ser discutido (e problematizado) em pesquisas que envolvam narrativas. Em vista disso, o aparato teórico e metodológico da Linguística SistêmicoFuncional (Halliday 1978, 1985, 1994, 2004; Eggins 2004; Eggins \& Martin 1997; Martin 2001; Martin \& Rose 2003; Thompson 2004) pode lançar luz sobre as pesquisas com narrativas e preencher algumas das lacunas apresentadas nas críticas de Pavlenko (2007).

Seguindo a definição de gênero do discurso de Martin (2001), que se inspirou na teoria sistêmica da linguagem (Halliday 1978), neste trabalho as narrativas de aprendizagem de línguas são consideradas um gênero do discurso com características marcadas, porque são tidas como processos sociais de representação de uma experiência de mundo específica, orientadas pelo objetivo de narrar essa experiência para um ou mais ouvintes ou leitores, por meio de estágios que representam os eventos vividos pelo narrador. As narrativas de aprendizagem de línguas, como gênero do discurso, são instanciadas ${ }^{3}$ a partir de três elementos: o "campo" (field), ou as ações

3. Halliday (2004:33) explica que um texto é o produto da combinação de dois processos que a teoria sistêmica conceitua como instanciação e realização. Isto é, a instanciação é a representação de um conjunto finito de escolhas disponível no sistema de cada língua, ao passo que a realização é a forma de materialização dessas escolhas em texto. 
sociais das personagens envolvidas na narrativa (o que elas fazem e como experienciam essas ações?), a "relação" (tenor), ou a estrutura dos papéis sociais de cada personagem das narrativas (qual é o status social de cada personagem e quais as relações hierárquicas que subjazem a esse status?) e o "modo" (mode), ou organização simbólica do "campo" e das "relações" em linguagem (que papel a linguagem exerce na representação das ações sociais das personagens e de suas relações sociais?). Esses três elementos constituem o registro, ou sistema semiótico representado por meio da linguagem (Martin 2001).

Martin \& Rose (2003) esclarecem que gêneros do discurso apresentam, em maior ou menor grau, as seguintes categorias linguístico-discursivas responsáveis pela instanciação das realidades sócio-históricas e culturais dos produtores do texto: "Avaliatividade" (Appraisal), ou sistema interpessoal que indica avaliação sobre atitudes negociadas no texto; "Ideação" (Ideation), ou sistema experiencial (transitividade) que focaliza o conteúdo do discurso, isto é, os tipos de atividades realizadas pelos participantes das narrativas e suas descrições; "Conjunção" (Conjuction), ou sistema lógico-experiencial que descreve e analisa as interconexões interfrasais aditivas, comparativas, sequenciais e explicativas; "Identificação" (Identification), ou sistema de identificação de participantes ou atores nas narrativas - quem são e do que se constituem; e, por fim, "Periodicidade" (Periodicity), ou fluxo da informação, indicando como os significados são organizados textualmente (tematização) a fim de que leitores possam processar as fases desses significados. Com base nesse modelo, podemos afirmar que ao narrarmos em primeira pessoa eventos sociais dos quais participamos, avaliamos os outros e nós mesmos, representamos nossas ações com os outros e organizamos tais representações por intermédio de discursos coesos e coerentes.

Expandindo as discussões aventadas em Rodrigues-Júnior (2008), focalizo a análise nos elementos de ideação, avaliatividade e fluxo da informação (em relação a este último, o foco recai sobre a tematização) das narrativas investigadas, com os objetivos de:

(i) Mapear os elementos semântico-discursivos de ideação, avaliatividade e tematização presentes no gênero do discurso narrativas de aprendizagem de línguas, à luz da teoria de gênero de Eggins \& Martin (1997) e Martin (2001), e do modelo de análise textual de Martin \& Rose (2003), de aprendizes brasileiros de inglês diante das escolhas linguísticas feitas por 
seus relatores para expressar suas experiências no processo de aquisição de uma língua estrangeira;

(ii) Expandir o esquema de análise linguístico-discursiva dessas narrativas, apresentado originalmente em Rodrigues-Júnior (2008), com o objetivo de descrever alguns elementos textuais de ideação, avaliatividade e tematização das narrativas de aprendizagem de línguas investigadas neste trabalho.

No que se segue, faço uma síntese das pesquisas linguísticas com narrativas, legatárias da abordagem laboviana (Labov \& Waletsky 1967; Labov 1972), em seguida apresento as categorias sistêmicas para a análise do corpus deste artigo, discuto os dados, na tentativa de aplicar o modelo de Martin \& Rose (2003) à análise dessas narrativas e de traçar um esboço de esquema desse gênero, e, por fim, teço as considerações finais.

\section{NARrativas NA PESQUisa linguística}

O modelo de Labov (Labov \& Waletzky 1967; Labov 1972) para análise linguística de narrativas inspirou pesquisas no âmbito das Ciências Humanas e Sociais, com o objetivo de descrever e interpretar a experiência humana e suas representações por meio de histórias. Com base em dados de narrativas orais de grupos afro-descendentes da cidade de Nova York, Labov estabeleceu que a estrutura da narrativa é formada por orações que se ligam a eventos temporais do discurso relatado pelos indivíduos que contam a história. Ao perguntar a seus informantes "Você já se viu em uma situação na qual você corria sério risco de ser assassinado?”, Labov (1972) identificou que as narrativas que ele coletou, ou seja, "narrativas de perigo de morte”, como definiu Toolan (2001:153), eram constituídas pelos seguintes elementos: Resumo (sumarização da história como um todo, respondendo à seguinte questão: do que se trata a história?); Orientação (informação sobre atores, tempo, lugar e situações; ou seja, quem, quando, o quê e onde?); Complicação (o corpo principal da narrativa, ou ação, e suas formas de reelaboração da trama do enredo; isto é, o que aconteceu depois disso?); Avaliação (o ponto da história e o motivo de seu relato; em outras palavras, significa a raison d'être: aonde o narrador quer chegar?); Resolução (o resultado da ação: o que finalmente aconteceu?); e Coda (retorno ao momento atual da história, indicando o fim da narrativa). 
Embora a pesquisa de Labov tenha sido o ponto de partida para estudos de narratologia realizados por pesquisadores de diversas áreas de investigação, por exemplo, da Educação (Clandinin \& Connelly, 2000), das Ciências Sociais (Riessman 1993) e da Comunicação (Bell 1991), pesquisas mais recentes em narratologia tem sido desenvolvidas de modo a explicar e problematizar as formas de representação de realidades de mundo por meio de narrativas (Chase 2005; Pavlenko 2007, 2009). O que se problematizam nessas pesquisas são as formas por meio das quais os relatores imputam um "grau de verdade" às suas histórias. Tannen (1979), por exemplo, identificou que narradores expressam em suas histórias, em relação às suas experiências passadas, o que ela denomina de "estruturas de expectação", o que, de fato, influencia os modos de construção interpretativa da história e, sobretudo, do ponto de vista do narrador sobre o objeto relatado. Essa discussão levou esses estudiosos a perceberem que narrativas são representações de uma ou várias realidades vividas ou não vividas pelos relatores que contam a história, cujas construções linguísticas indicam que narrativas têm relação direta com os aspectos socioculturais de seus produtores (Heath 1983).

Das pesquisas realizadas nessa linha de discussão, são de meu conhecimento alguns trabalhos voltados para análises linguístico-discursivas de narrativas e seus elementos genéricos, como é o caso de Gee (1991), em que o autor apresenta uma abordagem linguística para análises de narrativas com foco em mudança de ritmos de fala, pausas e pontuações de fala. A partir de um exemplo de narrativa de uma jovem esquizofrênica, Gee demonstra que da organização da narrativa por ele investigada emergem construções discursivas sistemáticas, definidas como linha e estrofe, e, ao mesmo tempo, construções discursivas coerentes com o estado psicológico da narradora. Gee mostra, portanto, que a coerência da narrativa parte de uma realidade de mundo da narradora.

No campo teórico e metodológico da Linguística Sistêmico-Funcional, o extenso trabalho de Eggins e Slade (1997) parte do modelo pioneiro de descrição e análise de narrativas de Labov (Labov \& Waletzky 1967; Labov 1972) para estabelecer relações diretas entre os elementos das narrativas de seus informantes e os elementos constitutivos das três metafunções da linguagem desenvolvidas pela teoria sistêmica, a saber, as metafunções textual, interpessoal e ideacional. O objetivo principal da análise das autoras foi estabelecer uma estrutura genérica para histórias orais, subdivididas em narrativa, relato, anedota e exemplum (anedota de cunho moral), com as 
seguintes características, respectivamente: complicação, registro de eventos passados, evento notável e incidente. Ao longo das análises, Eggins \& Slade gravitaram entre a identificação desses elementos textuais e seu papel na constituição de ideologias dos relatores em relação a práticas sociais diversas, apontando para o papel político das narrativas como meio semiótico de prática social.

A pesquisa de Gee (1991), também legatária do modelo laboviano, parece ainda se sustentar numa descrição linguística bastante vinculada ao texto per se, sem, no entanto, apontar para eventos discursivos que transcendem os limites do texto em direção a eventos socioculturais pertinentes às realidades de mundo dos produtores das narrativas investigadas. Já a pesquisa de Eggins \& Slade (1997) preocupa-se em relacionar a instância textual ao registro no qual se vincula a narrativa, suscitando discussões relevantes acerca da constituição de narrativas e sua relação com a cultura.

\section{Perspectiva semântico-discursiva de Martin \& Rose}

\subsection{Ideação}

O conceito de ideação, tratado por Martin \& Rose (2003), parte das discussões feitas por Michael A. K. Halliday em sua Gramática SistêmicoFuncional (1985, 1994). Martin \& Rose esclarecem que a ideação está no conteúdo do discurso; ou seja, nas atividades realizadas, nos participantes que realizam tais atividades, assim como nos elementos linguísticos que traduzem e caracterizam esses mesmos participantes.

A fim de descreverem os aspectos da ideação, Martin \& Rose (2003) apontam para o papel dos processos (verbos), dos participantes (sujeitos vinculados aos processos) e das circunstâncias (advérbios, grupos adverbiais e sintagmas preposicionados) na superfície do discurso. De fato, a ideação é a carga semântica da oração em processo de representação das experiências de mundo dos participantes localizados nas regiões limítrofes de processos e circunstâncias a eles associados. Para fins de ilustração, utilizo uma narrativa de uma estudante de inglês como língua estrangeira.

Sou Isabel, faço inglês na FALE [Faculdade de Letras da UFMG]. Já estou no intermediário. Eu detesto inglês, porque acho que é uma língua de dominantes, mas chegou um momento na minha vida que eu descobri que é decisivo... a falta do inglês 
era uma fronteira na minha vida. Eu quero ser uma pessoa cidadã do mundo, então eu acho que estudar inglês é importante. Não faço nada fora de sala de aula pra aprimorar meu inglês. Às vezes, eu pego meus livros das aulas e tento estudar um pouco em casa, mas eu não gosto. Não gosto da música americana, não gosto dessas coisas. Gosto de Beatles porque Beatles marcou época. Eu faço dois cursos de inglês e estou tentando little by little, day by day botar essa língua na minha cabeça.

Martin \& Rose (2003) afirmam que os processos materiais, os quais indicam uma ação executada por um ator, direcionada, ou não, a uma meta, focalizam tipos de atividades. No exemplo em questão, Isabel lança mão de processos materiais para sinalizar, claramente, as atividades às quais se vincula. Um exemplo disso seria:

Excerto 1:

\begin{tabular}{|l|l|l|}
\hline faço $^{4}$ & inglês & na FALE \\
\hline Ator + Processo material & Meta & Circunstância de localização \\
\hline
\end{tabular}

Outra característica marcada do excerto em análise é a ocorrência frequente de processos mentais, que expressam sensações, sentimentos, desejos, anseios, entre outros aspectos, dos participantes diretamente ligados a esses processos, nesse caso, denominados experienciadores. No trecho em análise, Isabel usa processos mentais para indicar seus sentimentos em relação à língua inglesa. Como exemplo, temos:

Excerto 2:

\begin{tabular}{|l|l|l|l|}
\hline Eu & detesto & inglês & $\begin{array}{l}\text { porque acho que é uma } \\
\text { língua de dominantes... }\end{array}$ \\
\hline Experienciador & Processo mental & Fenômeno & $\begin{array}{l}\text { Expansão por intensificação } \\
\text { causal }\end{array}$ \\
\hline
\end{tabular}

Os processos relacionais, por sua vez, indicam estados constituídos por experiências subjetivas e objetivas de seus portadores, a partir de atributos a eles vinculados. Um exemplo disso encontra-se na seguinte assertiva de Isabel:

4. Em língua portuguesa, a ocorrência comum de participantes elididos no processo caracteriza o processo tanto como elemento que representa o processo per se, como participante inserido na carga semântica do processo. Para discussões sobre esse fenômeno linguístico da língua portuguesa, à luz da teoria sistêmica, ver Gouveia \& Barbara (2004). 
Excerto 3:

\begin{tabular}{|l|l|l|}
\hline Eu & quero ser & uma cidadã do mundo \\
\hline Portador & Processo relacional: ser & Atributo \\
\hline
\end{tabular}

É curioso perceber que o processo relacional "ser" forma-se a partir do composto com o processo mental "quero", o qual instancia experiências internas, subjetivas, de mundo. Nesse sentido, Isabel traduz seus anseios por meio de desejos de se tornar alguém com características peculiares, nesse caso, "uma cidadã do mundo". Esse aspecto indica, por assim dizer, um hibridismo entre os dois tipos de processos, mental e relacional, escolhidos por Isabel para representar sua realidade ou experiências de aprendizagem. Veremos nas análises mais adiante que os relatos investigados carregam estruturas genéricas diretamente ligadas aos processos escolhidos pelos relatores para traduzirem suas experiências de mundo. A esse respeito, é pertinente esclarecer que, segundo Halliday (2004:174),

[p]arte do 'sabor' de um texto particular, e também do registro ao qual ele pertence, se encontra na mistura de tipos de processos. (...) A mistura de tipos de processos característica de um texto pertencente a um registro particular tipicamente se modifica no curso progressivo do texto. Por exemplo, o contexto ou orientação de uma narrativa é frequentemente composto por orações 'existenciais' e 'relacionais'; porém, a principal linha de evento é construída predominantemente por orações 'materiais'.

No caso do relato de Isabel, além dos processos materiais, os processos mentais constituíram-se igualmente na "principal linha do evento" da construção da narrativa feita por ela, indicando que os processos mentais por ela escolhidos expressaram suas experiências subjetivas de mundo em relação ao aprendizado de língua inglesa.

Há ainda os processos verbais, constituídos por meio de verbos em discurso direto ou indireto e realizados discursivamente por participantes denominados dizentes, e os comportamentais, inseridos na região limítrofe entre processos materiais e mentais, apontando comportamentos de seus

5. Minha tradução de: "Part of the 'flavour' of a particular text, and also of the register that it belongs to, lies in the mixture of process types. (...) The mixture of process types characteristic of a text belonging to a particular register typically changes in the course of unfolding of the text. For example, the setting or orientation of a narrative is often dominated by 'existential' and 'relational' clauses, but the main event line is construed predominantly by 'material' clauses'”. 
comportantes. No caso do corpus desta pesquisa, os processos materiais, mentais e relacionais ocorrem com uma frequência maior, ao passo que os verbais e comportamentais ocorrem em menor escala. Em alguns dos relatos temos casos de processo verbal, qual seja, “... ela falou $<$ processo verbal > com todo mundo...", e comportamental, como, por exemplo, "o importante para estudar Inglês é sempre rever a matéria, ouvir < processo comportamental $>$ a fita do livro que estudo". Note-se que a relação direta dos processos comportamentais com os materiais inclui esses processos no rol de escolhas linguísticas dos narradores para descreverem atividades em geral, como o exemplo em que o relator ouve as fitas cassetes do livro como exercícios de fixação e prática de compreensão.

\subsection{Avaliatividade}

No que tange à avaliatividade, Martin \& Rose (2003) a definem como uma caracterização de avaliação e julgamento presentes em escolhas lexicais dos produtores do discurso. A avaliatividade caracteriza as atitudes dos participantes do discurso, por meio de elementos linguísticos que sinalizam seus sentimentos, julgamentos e apreciações, em sua maioria, adjetivos, grupos nominais e advérbios de modo e de intensidade. Segundo Thompson (2004:75), ao usarmos o sistema de avaliatividade, estamos utilizando recursos linguísticos localizados no limiar da gramática, visto que a carga semântica da avaliatividade está muito mais nas escolhas lexicais que fazemos do que nas estruturas gramaticais que construímos.

Neste artigo, os elementos de avaliatividade serão tratados à margem da ideação, dependendo desta para a construção de significados e valores nos discursos dos relatores. Como exemplo, retomemos as experiências de Isabel:

Excerto 4:

\begin{tabular}{|l|l|l|l|}
\hline Eu & detesto & inglês & $\begin{array}{l}\text { porque acho que é uma língua } \\
\text { de dominantes... }\end{array}$ \\
\hline Experienciador & Processo mental & Fenômeno & $\begin{array}{l}\text { Expansão por intensificação } \\
\text { causal }\end{array}$ \\
\hline
\end{tabular}

A escolha de Isabel pelo processo mental "detesto" indica o peso do valor negativo que ela imputa à língua inglesa. Nesse caso, Isabel não 
precisou incluir um intensificador, como, por exemplo, uma circunstância de modo, ao processo mental [talvez, "detesto intensamente”], uma vez que seria uma redundância, dada a carga semântica negativa já imposta ao processo mental "detesto". Martin \& Rose (2003:31) se posicionam a esse respeito, argumentando contra a afirmação de que a "tecnicalidade [da ideação a] subtrai totalmente de [seu] papel avaliativo"“6, visto que os processos também podem exprimir em seus significados aspectos de julgamento e avaliação, tal qual acontece no sistema de avaliatividade quando do uso de adjetivos, grupos nominais e advérbios de modo e de intensidade que expressem algum tipo de avaliação.

Ademais, a expansão por intensificação causal do excerto 4 realiza-se $e^{7}$ pelo processo mental "acho" e pela projeção "que é uma língua de dominantes", por meio da qual Isabel avalia negativamente a língua inglesa caracterizando-a como bem cultural de povos economicamente desenvolvidos. Expansões desse tipo servem para, segundo Halliday (2004), apresentar informações adicionais à oração principal, ora refinando a informação dada, ora acrescentando novos comentários a seu respeito.

\subsection{Tematização}

Para Martin \& Rose (2003), a tematização contribui para o fluxo da informação de um texto, ou seja, como os significados são formatados de modo a apreender-lhes o conteúdo semântico em relação às outras escolhas linguístico-discursivas presentes no continuum das informações apresentadas no texto. A tematização dá a ideia de proeminência ou foco informacional (Halliday 2004:89) que representa o ponto de partida de um tópico oracional. Martin \& Rose (2003) esclarecem que a tematização orienta e localiza a oração dentro do contexto em que se insere a mensagem realizada em texto. Ao tematizarem essa ou aquela informação, os produtores do texto conferem certa ênfase ao conteúdo semântico do tema em relação às informações que o sucedem.

Admitindo-se que a tematização organiza a mensagem em texto, Thompson (2004), com base em Halliday (2004), apresenta dois tipos de

6. Minha tradução de: “... technicality [of ideation] totally robs [the latter] of [its] evaluative role".

7. Ver nota de rodapé no 3 . 
temas que podem ocorrer simultaneamente ou não em uma única oração, a saber, tema experiencial e tema múltiplo. Para Thompson (2004:159), esses tipos de temas referem-se aos três tipos de significados da oração: significados experiencial, interpessoal e textual. O tema que apresenta um elemento que cumpre um papel no sistema de transitividade (participante, processo ou circunstância) é denominado tema experiencial ${ }^{8}$; o que cumpre um papel múltiplo, no âmbito do modo oracional ou da função textual, é denominado tema múltiplo. Ressalte-se, porém, que, na ordem dos elementos léxico-gramaticais de uma oração, os temas múltiplos antecedem o tema experiencial. Retomando a narrativa de Isabel, temos alguns exemplos de tematização:

Excerto 5:

\begin{tabular}{|l|l|l|}
\hline Então & estou & no intermediário \\
\hline Tema textual & Tema experiencial & Rema $^{9}$ \\
\hline
\end{tabular}

O conector "então" expressa uma função textual conclusiva e o tema experiencial "estou" aponta para a experiência de mundo de Izabel, na qual ela se identifica como aprendiz de língua inglesa que se localiza em um nível específico de proficiência.

Excerto 6:

\begin{tabular}{|l|l|l|}
\hline Às vezes & eu & pego meus livros das aulas... \\
\hline Tema interpessoal & Tema experiencial & Rema \\
\hline
\end{tabular}

O composto adverbial de frequência "Às vezes" cumpre um papel de adjunto modal da função interpessoal, exercendo a função de adjunto circunstancial (Thompson 2004:63), porque responde à pergunta "com que frequência?", e o tema experiencial "eu" cumpre o papel de ator do processo

8. Halliday (2004:79) denomina esse tipo de tema como tema tópico. Thompson (2004:159), no entanto, prefere conceituá-lo como tema experiencial, porque “'tópico' é notoriamente um conceito movediço e, como muitas pessoas que trabalham com a abordagem hallidayana, eu prefiro evitar, nesse contexto, essa denominação. Portanto, vou simplesmente manter-me ao rótulo 'tema experiencial'. [Minha tradução de: “... 'topic' is a notoriously shifty concept, and, like many people working in the Hallidayan approach, I prefer to avoid it in this context; so I will simply keep to the label 'experiential Theme'”]. Adoto, no âmbito desta pesquisa, o conceito de tema experiencial, por concordar com Thompson acerca dos problemas de interpretação comuns ao termo 'tópico'.

9. A parte da oração menos o tema é denominada rema, ou parte da oração em que o tema se desenvolve (Halliday 2004: 64). Para os propósitos deste artigo, as análises centrar-se-ão nos elementos de tematização. 
material "pego". Adjuntos circunstanciais também explicitam informações adicionais na oração ao responderem questionamentos como: "quando", "como", "onde" ou "por que" o evento aconteceu? Esses adjuntos, pois, revelam-se elementos linguísticos importantes para o entendimento do processo de aprendizagem de língua estrangeira vivido por seus narradores, porque, em sua maioria, ilustram o modo por meio do qual esses narradores aprendem a língua estrangeira.

\section{Características genéricas das NARrativas DE APRENDiZAGEM}

Eggins \& Martin (1997) se pautam nas análises de registro e gênero para identificarem diferenças e semelhanças entre textos, partindo do nível da léxico-gramática hallidayana até atingir o nível do registro, apontando para aspectos culturais aos quais se vinculam os textos. Segundo Martin \& Rose (2003:252),

[p]or definição, um campo é um conjunto de sequências de atividades que são orientadas para certo propósito global dentro de instituições de família, comunidade ou sociedade. As sequências de atividades, as matrizes semióticas em cada passo de uma sequência e suas taxonomias de participantes criam expectativas para o desenvolvimento do campo do discurso. ${ }^{10}$

O conceito de registro para Eggins \& Martin (1997) origina-se das escolhas que fazemos como falantes de uma determinada língua para representarmos, por meio da linguagem, nossas realidades de mundo. Para eles, "[o] conceito de registro é uma explicação teórica da observação do senso-comum de que nós usamos diferentemente a linguagem em situações distintas"11 (Eggins \& Martin 1997:234, ênfase no original).

Um ponto fundamental expresso por Eggins \& Martin é o fato de que as escolhas léxico-gramaticais feitas são probabilísticas, conforme o contexto de situação onde se insere o(a) falante. Em outras palavras, o contexto de

10. Minha tradução de: "By definition a field is a set of activity sequences that are oriented to some global purpose within the institutions of family, community or society. The activity sequences, the figures in each step of a sequence, and their taxonomies of participants create expectations for the unfolding field of a discourse".

11. Minha tradução de: "The concept of register is a theoretical explanation of the common-sense observation that we use language differently in different situations". 
situação estabelece que escolhas serão feitas para servirem aos propósitos comunicativos de falantes inseridos nesse contexto. Rodrigues-Júnior (2006:40-1) esclarece esse ponto:

Halliday (1973:72-4) define significado potencial como um conjunto de escolhas, ou alternativas, de significados (semânticos) do sistema da língua disponível aos falantes/ escritores ou ouvintes/leitores. Para Halliday, o contexto de cultura define o significado potencial da linguagem à medida que esta é usada em registros diferenciados por falantes e escritores. Assim, em determinados registros, ou variedades funcionais da linguagem, a probabilidade de certas expressões ocorrerem em detrimento de outras depende da situação em que são utilizadas e da cultura que elas representam. (ênfase no original)

Segundo Schleppegrell (2004:51), "o campo do discurso, ou do assunto do qual a linguagem trata, está intimamente ligado às noções ordinárias do que significa utilizar a linguagem de maneira efetiva". ${ }^{12}$ A realização linguística da variável de campo do registro ocorre sobretudo por meio de substantivos, verbos e outras expressões que Schleppegrell (2004:51) denomina "palavras de conteúdo" (content words). Ou seja, a realização linguística do registro se dá, entre outras maneiras, por meio da ideação e de suas possibilidades avaliativas, conforme discutido anteriormente.

Além dessas expressões, há também os elementos de tematização (tema experiencial, temas múltiplos e temas marcados) que configuram o corpus desta pesquisa como textos que apresentam escolhas léxico-gramaticais que traduzem focos oracionais específicos, de conformidade com os objetivos comunicativos de seus produtores. A tematização está diretamente vinculada ao modo do registro, ou escolhas textuais que realizam as experiências de mundo dos participantes e suas relações interpessoais.

As variáveis de campo e modo do registro se expressam conforme a realização linguística apresentada no Quadro 1, tendo como base Schleppegrell (2004:47):

12. Minha tradução de: “... the field of discourse, what the language is about, is closest to ordinary notions of what it means to use language effectively". 
Quadro 1: Gramática e Contexto de Situação

\begin{tabular}{|c|c|}
\hline VARIÁVEIS DE CAMPO E MODO & REALIZAÇÃO LINGUÍSTICA \\
\hline APRESENTAÇÃO DE IDEIAS (Campo) & $\begin{array}{l}\text { - Sintagmas nominais/grupos nominais } \\
\text { (participantes); } \\
\text { - Verbos (tipos de processos); } \\
\text { - Sintagmas preposicionados, adjuntos e outros } \\
\text { recursos para informação sobre tempo, lugar, } \\
\text { modo, etc. (circunstâncias); } \\
\text { - Recursos para elaboração de relações lógicas } \\
\text { (sobretudo expansões). }\end{array}$ \\
\hline ESTRUTURAÇÃO DO TEXTO (Modo) & $\begin{array}{l}\text { - Organização temática ou tematização (tema } \\
\text { experiencial, temas múltiplos e marcados). }\end{array}$ \\
\hline
\end{tabular}

Nesse sentido, os itens do Quadro 1 formam o conjunto de elementos que representa linguisticamente as características genéricas das narrativas de aprendizagem de línguas investigadas nesta pesquisa.

\section{Metodologia}

Eggins \& Martin (1997) afirmam que todo gênero do discurso apresenta estruturas esquemáticas em cada estágio de sua constituição. Tal afirmação surge de discussões apresentadas por Martin (1984) e revisitadas posteriormente em Martin (2001), em cujo trabalho o teórico afirma que um gênero é uma atividade composta por estágios, com propósitos bem definidos e orientados para fins específicos, por meio dos quais falantes e escritores se engajam para representarem suas visões de mundo e, sobretudo, posicionarem-se como membros de uma dada cultura.

Seguindo as orientações de Martin (2001) e Eggins \& Martin (1997), a seleção do corpus desta pesquisa foi feita tendo em mente o mapeamento dos elementos linguísticos apresentados no Quadro 1, conforme apresentado no primeiro objetivo deste artigo. Os dados são compostos por trinta e sete transcrições de narrativas em áudio de aprendizes de inglês como língua estrangeira, extraídas da homepage do Projeto AMFALE ${ }^{13}$. As narrativas

13. AMFALE é o acrônimo de Aprendendo com Memórias de Falantes e Aprendizes de Língua Estrangeira, projeto idealizado pela Prof. ${ }^{a}$ Vera Menezes, da Faculdade de Letras da UFMG. O projeto pode ser acessado em http://www.veramenezes.com/narrativas.htm.. 
surgiram de entrevistas realizadas por graduandos em Letras da UFMG e por pesquisadores do projeto AMFALE. Essas mesmas narrativas também foram analisadas tendo em mente as categorias de ideação, avaliatividade e tematização propostas por Martin \& Rose (2003). Além disso, após ler as narrativas e identificar os processos usados pelos relatores e os temas experiencial e múltiplo, parti para a categorização desses elementos léxicogramaticais e a identificação dos tipos de processos e temas que ocorriam em cada parte, ou estágio, dessas narrativas. O Quadro 2 mostra as categorias de cada estágio analisado, ressaltando-se a uniformidade de tipos de processos e temas neles presentes, o que indica, a priori, a existência de uma estrutura genérica comum às narrativas investigadas.

Nesta pesquisa, narrativas de aprendizagem de línguas são tidas como formas linguístico-discursivas de representação de estratégias e mecanismos que os estudantes de uma língua estrangeira utilizam para atingir níveis de proficiência desejáveis. Os dados desta pesquisa mostram que, no geral, as narrativas de aprendizagem apresentam três estágios distintos, embora interligados, dada sua ocorrência no corpus investigado. Por meio dessas narrativas, os aprendizes de inglês como língua estrangeira expressam suas visões de mundo acerca da língua inglesa, através de estágios bem caracterizados desse gênero.

Quadro 2: Estágios do gênero narrativas de aprendizagem de línguas

\begin{tabular}{|l|l|l|l|}
\hline $\begin{array}{l}\text { Estágios } \\
\text { funcionais } \\
\text { de estruturas } \\
\text { esquemáticas }\end{array}$ & $\begin{array}{l}\text { Domínio } \\
\text { oracional }^{14}\end{array}$ & $\begin{array}{l}\text { Propósitos dos } \\
\text { estágios }\end{array}$ & $\begin{array}{l}\text { Realizações linguístico- } \\
\text { discursivas mais } \\
\text { frequentes }\end{array}$ \\
\hline $\begin{array}{l}\text { Estágio 1: } \\
\text { Identificação, } \\
\text { primeiro contato } \\
\text { e início da } \\
\text { aprendizagem. }\end{array}$ & De 01 a 03 & $\begin{array}{l}\text { Identificar } \\
\text { participantes; relatar } \\
\text { primeiro contato } \\
\text { com a língua-alvo; } \\
\text { posicionar-se perante } \\
\text { as experiências de } \\
\text { aprendizagem. }\end{array}$ & $\begin{array}{l}\text { - Processos relacionais, } \\
\text { materiais e mentais. } \\
\text { - Identificação dos relatores } \\
\text { por meio de processos } \\
\text { relacionais. } \\
\text { - Ocorrência de temas } \\
\text { experienciais e temas } \\
\text { marcados (estes } \\
\text { identificando, pelo nome, os } \\
\text { aprendizes). }\end{array}$ \\
\hline
\end{tabular}

14. O domínio oracional pode ser diferente, em termos de número de orações, conforme o número de palavras de cada narrativa. 


\begin{tabular}{|c|c|c|c|}
\hline $\begin{array}{l}\text { Estágio 2: } \\
\text { Características de } \\
\text { aprendizagem. }\end{array}$ & De 04 a 20 & $\begin{array}{l}\text { Relatar métodos de } \\
\text { aprendizagem da } \\
\text { língua-alvo. }\end{array}$ & $\begin{array}{l}\text { - Ocorrência de processos } \\
\text { materiais. } \\
\text { - Ocorrência de } \\
\text { Circunstâncias de extensão e } \\
\text { de modo. } \\
\text { - Expansão por meio } \\
\text { de verbos não-finitos e } \\
\text { conjunções aditivas, mais } \\
\text { comumente a conjunção } \\
\text { "e". } \\
\text { - Ocorrência de temas } \\
\text { textuais denotando } \\
\text { continuidade ou } \\
\text { fluxo do discurso, } \\
\text { descrevendo estratégias de } \\
\text { aprendizagem. } \\
\text { - Ocorrência de temas } \\
\text { experienciais, com } \\
\text { ocorrência do participante } \\
\text { "eu”. } \\
\text { - Ocorrência de temas } \\
\text { interpessoais (adjuntos } \\
\text { circunstanciais, e.g. } \\
\text { "sempre", "em sala de } \\
\text { aula"). } \\
\text { - Apreciações explícitas } \\
\text { e implícitas (através de } \\
\text { processos sobretudo } \\
\text { mentais). }\end{array}$ \\
\hline $\begin{array}{l}\text { Estágio 3: } \\
\text { Declaração do } \\
\text { sucesso ou insucesso } \\
\text { da aprendizagem; } \\
\text { previsões de } \\
\text { continuidade dos } \\
\text { estudos na língua- } \\
\text { alvo. }\end{array}$ & De 20 a 30 & $\begin{array}{l}\text { Relatar os sucessos } \\
\text { ou insucessos da } \\
\text { aprendizagem e a } \\
\text { continuidade dos } \\
\text { estudos na língua- } \\
\text { alvo. }\end{array}$ & $\begin{array}{l}\text { - Ocorrência de processos } \\
\text { materiais, mentais e } \\
\text { relacionais. } \\
\text { - Expansão com verbos não- } \\
\text { finitos. } \\
\text { - Ocorrência de } \\
\text { circunstâncias de modo. } \\
\text { - Ocorrência de temas } \\
\text { textuais denotando } \\
\text { continuidade ou fluxo } \\
\text { do discurso, por meio de } \\
\text { avaliações e conclusões } \\
\text { das experiências de } \\
\text { aprendizagem. } \\
\text { - Ocorrência de temas } \\
\text { interpessoais. } \\
\text { - Ocorrência de temais } \\
\text { experienciais, sobretudo o } \\
\text { participante "eu". }\end{array}$ \\
\hline
\end{tabular}


A ocorrência de tipos de processos e de temas em cada estágio do gênero em análise aponta para a caracterização desse gênero como instância discursiva que se constitui a partir dos processos e temas escolhidos pelos relatores para descreverem suas experiências de aprendizagem e seus posicionamentos frente a essas experiências. No que se segue, apresento algumas análises da ideação avaliativa e da tematização nos diferentes estágios constitutivos do gênero narrativas de aprendizagem de línguas estrangeiras.

\section{Análises}

\section{Estágio 1: Identificação, primeiro contato e início da aprendizagem}

Os elementos linguístico-discursivos comumente usados pelos aprendizes no Estágio 1 de suas narrativas apontam para a identificação do narrador, o primeiro contato com a língua-alvo e o início da aprendizagem. Processos materiais são escolhidos, em sua maioria, para representarem atividades executadas pelos narradores no processo de aprendizagem, ao passo que processos relacionais e mentais são usados para indicar relações com a língua inglesa e avaliações a seu respeito. Alguns exemplos mostram claramente essas características.

Excerto 7: Aluno 1

\begin{tabular}{|l|l|l|}
\hline O ensino & era & insuficiente e muito deficitário \\
\hline Portador & Processo relacional & Atributo \\
\hline
\end{tabular}

No excerto 7, o narrador posiciona-se perante o ensino, demonstrando atributos negativos em relação a ele. Nesse caso, o portador desses atributos é "o ensino", caracterizado pelo processo relacional "era". Além disso, há um peso semântico de avaliação negativa no excerto 7, sem, necessariamente, a presença de advérbios de modo e de intensidade, vinculados ao processo, que expressassem esse tipo de avaliação. Portanto, no excerto 7 os elementos no entorno do processo relacional, especificamente o atributo, já exercem o papel semântico-discursivo de avaliatividade.

Excerto 8: Aluna 2

\begin{tabular}{|l|l|l|l|}
\hline $\mathrm{Eu}$ & estudei & na PUC & quatro anos e meio \\
\hline Ator & Processo material & $\begin{array}{l}\text { Circunstância de } \\
\text { localização }\end{array}$ & Circunstância de tempo \\
\hline
\end{tabular}


O excerto 8 aponta para o papel dos processos materiais como elementos discursivos que indicam a execução de atividades realizadas pelos narradores. As circunstâncias de localização e de tempo, por sua vez, caracterizam a atividade por meio de sua particularização no tempo e em localidade específica. Vê-se, pois, que as circunstâncias de localização e de tempo, compreendidas aqui como parte constitutiva da oração experiencial, não apenas conferem informações adicionais à estrutura experiencial do grupo verbal, mas, sobretudo, constituem-se em informação extra para o entendimento da experiência vivida no relato, uma vez que conferem à realidade de mundo da narradora um tempo específico para a sua capacitação.

Excerto 9a: Aluna 3

\begin{tabular}{|l|l|l|}
\hline Eu & sou & advogada, professora universitária,... \\
\hline Portador & Processo relacional & Atributo \\
\hline
\end{tabular}

Excerto 9b: Aluna 3

\begin{tabular}{|l|l|l|}
\hline ... estou fazendo & letras [sic] & porque eu gosto,... \\
\hline Ator + Processo material & Meta & Expansão por intensificação causal \\
\hline
\end{tabular}

Excerto 9c: Aluna 3

\begin{tabular}{|l|l|l|l|}
\hline ... e eu & estou fazendo & Inglês & porque eu gosto \\
\hline Ator & Processo material & Meta & $\begin{array}{l}\text { Expansão por intensificação } \\
\text { causal }\end{array}$ \\
\hline
\end{tabular}

O excerto 9, desmembrado em três momentos, demonstra, respectivamente, a identidade da relatora (excerto 9a), a justificativa de uma atividade realizada por ela (excerto 9b) e a especificação e justificativa de uma atividade vinculada a outra atividade (excerto 9c), nesse caso, o curso de língua inglesa vincula-se ao de Letras. O excerto 9a mostra claramente o uso do processo relacional "sou" como elemento semântico-discursivo que expressa a identidade da relatora por meio do atributo "advogada". O excerto $9 \mathrm{~b}$ é peculiar, dada a presença da expansão por intensificação causal "porque eu gosto" como justificativa subjetiva, portanto, representada por meio do processo mental "gosto", tal qual acontece no excerto 9c.

Em termos de tematização, há também uma variedade de escolhas feitas pelos narradores no Estágio 1, embora a ocorrência de temas experienciais prevaleça. 
Excerto 10: Aluno 5

\begin{tabular}{|l|l|}
\hline $\mathrm{Eu}$ & comecei a estudar inglês a partir do segundo grau. \\
\hline Tema experiencial & Rema \\
\hline
\end{tabular}

Temas experienciais, como o do excerto 10, marcam as experiências de aprendizagem dos narradores, localizando-os como agentes do processo, conforme percebido pelo processo material "comecei". A ocorrência desses tipos de tema se dá no estágio 1 das narrativas porque introduzem o aprendiz também como responsável por seu aprendizado e o localizam, na maioria das vezes, como agentes de ações que sinalizam o início do processo de aprendizagem da língua-alvo.

No que se refere à identificação explícita dos aprendizes, as escolhas temáticas frequentemente usadas para essa identificação trazem características marcadas, como pode ser visto no excerto 11.

Excerto 11: Aluno 10

\begin{tabular}{|l|l|}
\hline Meu nome é Rodrigo, & já estudo inglês há uns dez anos. \\
\hline Tema marcado & Rema \\
\hline
\end{tabular}

A identificação dos aprendizes é marcada pela presença do processo relacional "é", dentro da estrutura do tema marcado, iniciado atipicamente pelo pronome possessivo "Meu" e tendo como sujeito da oração relacional o substantivo "nome". Essa construção aponta para a e da identidade do aprendiz, também expressa pelo nome próprio "Rodrigo". Temas desse tipo ocorrem com certa frequência no corpus sob análise, fato linguístico que demonstra a relevância da identificação para os próprios aprendizes.

Há igualmente a possibilidade de desmembrar o tema marcado em partes que constituem um tema múltiplo, como mostra o excerto 12.

Excerto 12: Aluno 10

\begin{tabular}{|l|l|l|}
\hline Meu & nome & é Rodrigo... \\
\hline Tema textual & Tema experiencial & Rema \\
\hline
\end{tabular}

Pronomes possessivos, como "meu”, por exemplo, são, segundo Martin \& Rose (2003:149), "outra fonte importante para identificar participantes" 15 . Curioso, porém, é o fato de o elemento linguístico "nome"

15. Minha tradução de: "Another important resource for identifying participants..." 
ter-se tornado o conteúdo semântico da experiência relacional de Rodrigo. Ou seja, o tema experiencial "nome" exerce, nesse exemplo, papel semântico fundamental para a identificação do aprendiz. Ao tematizar sua narrativa com essa oração, Rodrigo identifica-se explicitamente e indica que todos os eventos relatados em sua narrativa são oriundos de sua visão de mundo e, consequentemente, das experiências que vivenciou durante o processo de aquisição da língua-alvo. A presença desses tipos de tema no corpus deste estudo indica um elemento linguístico marcado do estágio 1 das narrativas investigadas.

\section{Estágio 2: Características de aprendizagem}

Esse estágio é caracterizado por descrições de estratégias de aprendizagem da língua-alvo que os narradores utilizam ao longo do processo de aquisição, conforme pode ser visto nos excertos seguintes:

Excerto 13a: Aluno 3

\begin{tabular}{|l|l|}
\hline Peguei & livros elementares,... \\
\hline Ator + Processo material & Meta \\
\hline
\end{tabular}

Excerto 13b: Aluno 3

\begin{tabular}{|l|l|}
\hline$\ldots$ ia estudando & até os avançados,... \\
\hline Ator + Processo material & Circunstância de extensão \\
\hline
\end{tabular}

Excerto 13c: Aluno 3

\begin{tabular}{|l|l|}
\hline ... fazendo os exercícios & até adquirir uma fluência básica \\
\hline Expansão por elaboração & Expansão por extensão \\
\hline
\end{tabular}

O excerto 13, desmembrado em três momentos, mostra que seu relator lança mão, respectivamente, dos processos materiais "Peguei" (excerto 13a) e "ia estudando" (excerto 13b) para caracterizar as estratégias de aprender língua estrangeira como uma atividade. A meta do excerto 13a complementa-se na circunstância de extensão do excerto $13 \mathrm{~b}$, uma vez que o relator adota a técnica de estudar desde os "livros elementares" "até os avançados". As expansões por elaboração e extensão, respectivamente, "fazendo os exercícios" e "até adquirir uma fluência básica", presentes no excerto $13 \mathrm{c}$, sinalizam o uso de expansões com verbos não-finitos, isto é, verbos não conjugados, como é o caso de "fazendo" e "adquirir". O uso de expansões por elaboração com verbos não-finitos indica, segundo Martin 
\& Rose (2003), a elaboração do significado previamente dado na oração anterior. Assim, os narradores utilizam expansões para, nesse caso, elaborarem as informações de como eles aprendem a língua inglesa.

No que se refere à tematização, esse estágio caracteriza-se, sobretudo, por temas textuais indicando continuidade do discurso, por temas experienciais, com ocorrência do participante "eu", e por temas interpessoais, especificamente por meio de adjuntos circunstanciais.

Excerto 14: Aluno 4

\begin{tabular}{|l|l|l|}
\hline Então & optei & por fazer o Inglês. \\
\hline Tema textual & Tema experiencial & Rema \\
\hline
\end{tabular}

A ocorrência de temas textuais como o do excerto 14 indica, no discurso produzido pelos aprendizes, elementos semântico-discursivos que apontam para a continuidade da informação de como a língua inglesa é aprendida. Verifica-se, ainda, que o tema textual é parte constitutiva de um tema múltiplo em que o agente da ação, nesse caso expresso pelo processo material "optei", é representado linguisticamente como elemento responsável pela ação de escolher a língua inglesa como objeto de estudo.

Além de temas textuais, a ocorrência de temas experienciais com participante "eu" realiza-se, muitas vezes, por meio de temas múltiplos, em que também ocorrem temas interpessoais, mais precisamente, adjuntos circunstanciais, conforme pode ser visto no excerto 15 .

Excerto 15: Aluno 5

\begin{tabular}{|l|l|l|l|}
\hline Mas & hoje & eu & $\begin{array}{l}\text { procuro recuperar o tempo } \\
\text { perdido... }\end{array}$ \\
\hline Tema textual & Tema interpessoal & Tema experiencial & Rema \\
\hline
\end{tabular}

O complexo da tematização expresso no excerto 15 mostra que o aprendiz "eu" elabora seu discurso de modo a esclarecer que atualmente as estratégias de aprendizagem que ele utiliza referem-se à recuperação de um "tempo perdido" anteriormente. $\mathrm{O}$ tema múltiplo, pois, foi escolhido para traduzir o processo de aquisição da língua estrangeira pelo qual esse aprendiz tem passado. $\mathrm{O}$ tema interpessoal "hoje" (adjunto circunstancial de tempo) localiza a ação do aprendiz no tempo atual, caracterizando sua narrativa como um relato que se sustenta em experiências vividas (provavelmente frustrantes) para planejar ações futuras, conforme expresso no rema da oração. 
Estágio 3: Declaração do sucesso ou insucesso da aprendizagem; previsões de continuidade dos estudos na língua-alvo

Esse estágio representa os resultados do aprendizado da língua-alvo alcançados ao longo do processo de aquisição.

Excerto 16a: Aluno 4

\begin{tabular}{|l|l|}
\hline Acho & $\begin{array}{l}\text { que uma coisa que ajudou bastante foi o fato de os } \\
\text { professores não cobrar [sic] tanto,... }\end{array}$ \\
\hline Experienciador + Processo mental & Projeção \\
\hline
\end{tabular}

Excerto 16b: Aluno 4

\begin{tabular}{|l|l|l|l|l|}
\hline ... como era escola pequena, & todo mundo & me & recebeu & bem... \\
\hline $\begin{array}{l}\text { Expansão por intensificação } \\
\text { causal }\end{array}$ & Ator & Meta & Processo material & $\begin{array}{l}\text { Circunstância de } \\
\text { modo }\end{array}$ \\
\hline
\end{tabular}

O excerto 16, desmembrado em dois momentos, mostra que o processo mental "Acho" (excerto 16a) é usado pelo relator para exprimir sua avaliação acerca do curso, como pode ser visto na projeção "que uma coisa que ajudou bastante foi o fato de os professores não cobrar [sic] tanto,...". É comum que processos mentais projetem ideias representadas em outras orações, com o objetivo, segundo Halliday (2004), de representar o conteúdo subjetivo, nesse caso, do narrador. $\mathrm{O}$ que vale ressaltar no excerto 16a é o papel semântico do processo mental em expressar a avaliação do relator sobre o curso de idiomas do qual ele participava, cuja figura avaliada são os professores de línguas, como pode ser visto na projeção. Ademais, o processo mental "Acho" funciona como uma metáfora de modalidade, em cuja configuração o narrador deixa implícito que certamente "o fato de os professores cobrar [sic] tanto" foi determinante para a continuidade de seus estudos ${ }^{16}$ (a esse respeito, ver Halliday 2004:613-4).

O excerto $16 b$ dá continuidade à avaliação do narrador. A expansão por intensificação causal "como era escola pequena" traduz-se como a causa da hospitalidade vivida pelo narrador no momento de sua entrada na escola. Essa característica indica que o narrador, antes de ser o agente da ação, recebe a hospitalidade, fato este registrado discursivamente no papel de meta assumido por ele. A circunstância de modo "bem" exprime,

16. Agradeço aos pareceristas da D.E.L.T.A. por terem chamado minha atenção para esse aspecto semântico-discursivo do processo mental "Acho" como metáfora de modalidade. 
mais uma vez, a avaliação positiva do narrador sobre a hospitalidade dos funcionários da escola.

Em relação à tematização, o estágio 3 segue os padrões linguísticos do estágio 2, no qual a ocorrência de temas textuais e experienciais denota, respectivamente, continuidade do discurso e agenciamento de participantes, além da ocorrência de temas interpessoais realizados por adjuntos circunstanciais. Um exemplo dessa escolha é o excerto 17.

Excerto 17: Aluno 27

\begin{tabular}{|l|l|l|l|}
\hline Então, & no geral, & foi & $\begin{array}{l}\text { uma experiência que se iniciou } \\
\text { muito boa... }\end{array}$ \\
\hline Tema textual & Tema interpessoal & Tema experiencial & Rema \\
\hline
\end{tabular}

Novamente, o tema múltiplo, constituído pelos temas textual ("Então"), interpessoal ("no geral") e experiencial ("foi") indica, respectivamente, continuidade do discurso, generalização da experiência vivida e identificação dessa experiência como uma experiência positiva, segundo o rema da oração. No estágio 3, portanto, os elementos semântico-discursivos da tematização informam que o processo de aprendizagem de uma língua estrangeira, sobretudo os resultados desse processo, estão claramente marcados no conteúdo oracional do discurso produzido pelos aprendizes.

Até o momento, as análises destacaram que: (i) a ideação pode expressar valores, julgamentos e opiniões, além de experiências acerca da aprendizagem de línguas vividas por seus relatores; (ii) a variedade de tipos de processos, circunstâncias e expansões demonstra que a complexidade da aprendizagem de uma língua estrangeira está presente nos discursos produzidos pelos aprendizes em suas narrativas; (iii) a tematização das narrativas investigadas mostra o fluxo informacional das características de aprendizagem, igualmente marcada nas escolhas dos temas (sobretudo múltiplos) feitas por seus narradores, com destaque na identificação dos aprendizes; (iv) os estágios funcionais do gênero narrativas de aprendizagem de línguas demostram que há uma espécie de padrão recorrente nessas narrativas, ora com características mais marcadas em alguns estágios, ora com aspectos mais comuns em outros. Com efeito, um dos objetivos desta pesquisa em andamento foi realizado, qual seja, discutir algumas características genéricas das narrativas, à luz da teoria de gêneros da Linguística Sistêmico-Funcional, de aprendizes brasileiros de inglês diante das esco- 
lhas linguísticas feitas por seus relatores para expressar suas experiências no processo de aquisição. Cabe, agora, partir para o esboço inicial de um esquema de análise linguístico-discursiva de narrativas de aprendizagem de línguas.

\section{EsBoçO DE UM ESQUEMA DO GÊNERO NARRATIVAS DE APRENDIZAGEM DE LÍNGUAS}

Com base nas categorias de transitividade, Simpson (1993), em seu livro Language, Ideology and Point of View, analisa a representação de personagens em gêneros de narrativa literária ficcional e não-ficcional. Esse teórico investiga principalmente o papel que as personagens exercem na trama das narrativas através dos processos eleitos para representá-las e quais circunstâncias periféricas ao processo oferecem informações sobre como, quando, onde e por que os processos ocorrem.

Explorando o papel das personagens em narrativas, Simpson (1993) estabelece duas categorias que ele denomina como: (i) narrativas dentro da categoria $A$, isto é, narrativas em primeira pessoa, narradas por um "personagem participante" (participating character); e (ii) narrativas dentro da categoria B, ou seja, narrativas em terceira pessoa, narradas por um personagem 'invisível', "desincorporado" (disembodied) da narrativa, portanto, um "narrador não-participante" (non-participating narrator). A preocupação central de Simpson é justamente compreender o ponto de vista ou ângulo da narrativa por meio da investigação da linguagem como representação ou projeção das perspectivas e posições de suas personagens. Para tanto, Simpson (1993:104) enfatiza a importância do sistema de transitividade, cujo objetivo central é

... tornar explícito como certos significados são destacados enquanto outros são suprimidos ou ofuscados. Dessa forma, o modelo de transitividade proporciona uma maneira de investigar como a percepção de um leitor ou ouvinte acerca do significado de um texto é direcionada para uma determinada interpretação e como a estrutura linguística de um texto efetivamente codifica uma 'visão de mundo' particular. ${ }^{17}$

17. Minha tradução de: “... to uncover how certain meanings are foregrounded while others are suppressed or obfuscated. In this way, the transitivity model provides one means of investigating how a reader's or listener's perception of the meaning of a text is pushed in a particular direction and how the linguistic structure of a text effectively encodes a particular 'world-view'. 
A partir das ponderações apresentadas por Simpson (1993), o corpus deste artigo insere-se no rol das narrativas positivas, isto é, narrativas homodiegéticas, em que "o narrador é uma personagem dentro da história"18 narrada. Essa posição do narrador em relação às histórias por ele relatadas faz com que seu ponto de vista narrativo realize uma espécie de "seleção" dos discursos produzidos pelos outros participantes das narrativas, representando-os linguisticamente por seu intermédio. Tal fato vai ao encontro da definição de ponto de vista narrativo dada por Simpson (1993:4): "[n]o contexto da narrativa (...), ponto de vista se refere geralmente à perspectiva psicológica por meio da qual uma história é contada". ${ }^{19}$

Em termos de tematização, as narrativas investigadas neste trabalho trazem características temáticas que as situam no rol de relatos que têm por objetivo o registro de eventos passados, como discutido por Eggins \& Slade (1997), mas que, em grande medida, também apontam para ações futuras, diferenciando-as do relato propriamente dito. Essa menção a ações futuras ocorre nos estágios 2 e 3 das narrativas analisadas, fato que revela a importância da tematização para o dinamismo comunicativo do discurso produzido pelos narradores (cf.: Martin \& Rose, 2003) e, sobretudo, para o entendimento dessas narrativas como registros de experiências e, ao mesmo tempo, planos de ação.

Para o esboço do esquema do gênero narrativas de aprendizagem de línguas (Figura 1), tomarei como base: (i) os elementos de ideação usados pelos relatores; (ii) o peso semântico de avaliatividade comumente presente nesses elementos; (iii) os elementos de tematização que marcaram cada estágio das narrativas; (iv) por fim, o ponto de vista narrativo dos relatores do corpus desta pesquisa.

18. Minha tradução de: “... a narrator is a character within the story".

19. Minha tradução de: "In the context of narrative (...), point of view refers generally to the psychological perspective through which a story is told". 


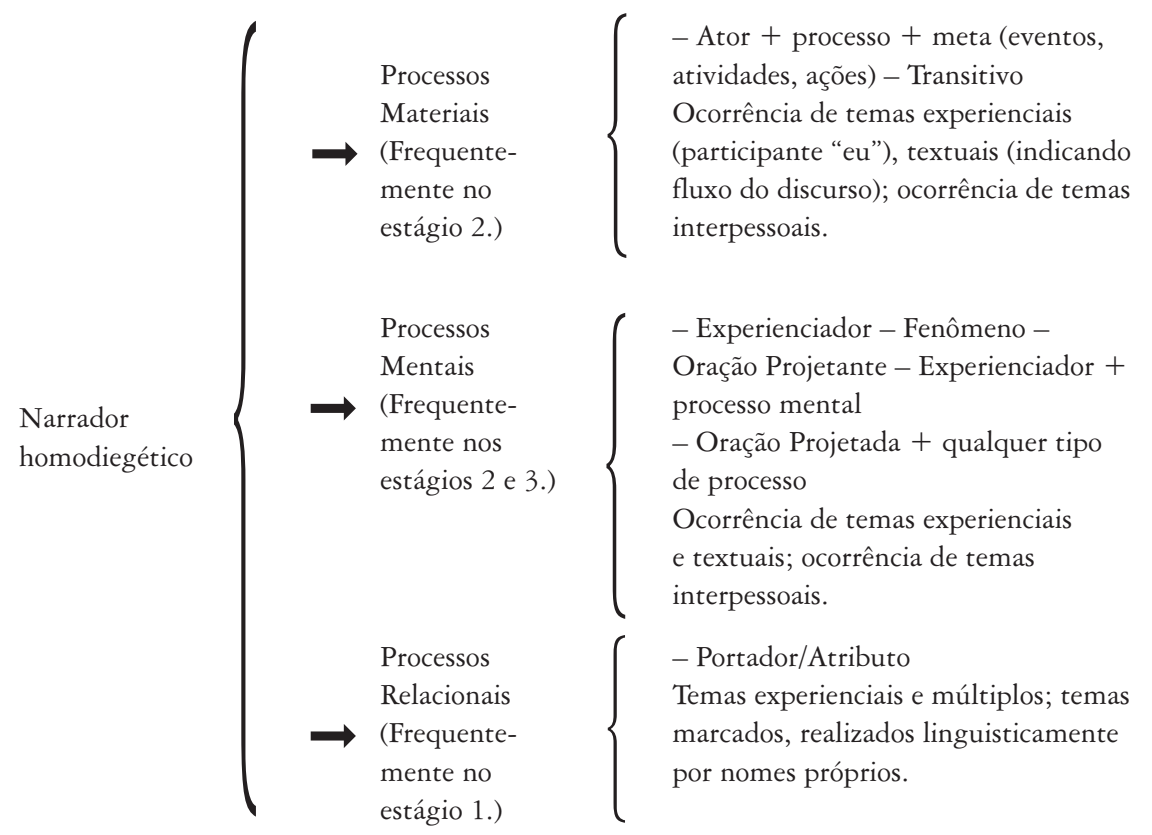

Figura 1: Esboço de um esquema de análise da ideação avaliativa e da tematização em narrativas de aprendizagem de línguas

O esquema apresenta os três tipos de processos que aparecem nas narrativas, sobretudo porque são usados pelos narradores para descreverem atividades realizadas (processos materiais, frequentemente no estágio 2, no qual são descritas as características e atividades de aprendizagem), para exprimirem opiniões e sentimentos (processos mentais, em sua maioria, nos estágios 2 e 3, nos quais são feitas avaliações em geral) e para se identificarem com os eventos por meio de atribuição de determinado valor (processos relacionais, com maior ênfase no estágio 1). Isso não significa, entretanto, que outros processos, como os comportamentais, verbais e existenciais, não ocorram. O que de fato se percebe é que a ocorrência destes últimos é menor, indicando que seus papéis semântico-discursivos talvez tenham funções discursivas menos relevantes nesse tipo de registro.

No que tange à tematização, os estágios 2 e 3 apresentam ocorrência de temas textuais e experienciais, embora os temas interpessoais, realizados linguisticamente por adjuntos circunstanciais, também ocorram. No estágio 1, os temas marcados, realizados linguisticamente por nomes próprios, sugerem que a identificação dos aprendizes caracteriza-os como agentes de 
ações desempenhadas ao longo do processo de aquisição da língua-alvo. É importante enfatizar que a ocorrência de temas se dá no entorno de processos eleitos pelos narradores para expressarem suas experiências de aprendizagem. Daí, portanto, o papel dos processos para a identificação dos temas no esboço proposto.

Conforme o esquema, há ocorrências de processos materiais indicando atividades em eventos específicos, a partir de verbos transitivos, como pôde ser visto nos exemplos analisados. Os processos mentais, por sua vez, exprimem sensações, opiniões e avaliações de seus relatores por meio da relação Experienciador - Fenônemo, bem como por meio de orações projetadas. Por fim, os processos relacionais são chamados à cena do discurso para identificarem os relatores, conferindo-lhes determinados atributos.

Partindo desse esquema, é-nos possível retomar o Quadro 2 e perceber que, no Estágio 1, a ocorrência de processos relacionais revela a identificação dos relatores; essa identificação também ocorre nos temas marcados, cuja construção semântico-discursiva se dá por meio de nomes próprios. No Estágio 2, a ocorrência de processos materiais e mentais mostra que eles servem para, respectivamente, descrever atividades e expressar sentimentos, sensações e avaliações a respeito da aprendizagem; a presença de temas experienciais e textuais, estes denotando o fluxo, ou continuidade, do discurso produzido pelos narradores, referem-se às características de aprendizagem da língua estrangeira e ao processo dessa aquisição. No Estágio 3, os três tipos de processos, quais sejam, materiais, mentais e relacionais, ocorrem simultaneamente, uma vez que os relatores oscilam entre as três construções de significados, embora os processos mentais também sejam convocados a servirem de recursos linguísticos na representação de avaliações e julgamentos feitos pelos relatores; novamente, os temas experienciais e textuais exercem, nesse estágio, o mesmo papel exercido no estágio 2. É-nos possível ainda compreender, a partir dos elementos de ideação avaliativa e tematização presentes nos dados, as narrativas investigadas como representações do ponto de vista de seus relatores, por meio dos quais estes últimos constroem realidades de mundo, julgamentos e avaliações de eventos por eles vividos. Nesse sentido, narrativas de aprendizagem de línguas são representações de uma realidade, uma vez que são seus relatores que constituem a mise en scène dos fatos relatados. 


\section{Considerações Finais}

Ao expandir suas discussões sobre linguagem, registro e gênero, Martin (2001) afirma que as narrativas apresentam inícios e fins mais elaborados, em que os estágios Orientação e Coda exprimem o ponto de vista principal da história, pelo fato de aquele introduzir o tópico da narrativa e de este dar-lhe um desfecho que sintetize a problemática desenvolvida ao longo do relato. No caso dos dados desta pesquisa, os estágios de Orientação e Coda resumem-se, respectivamente, em dois estágios obrigatórios (ver Quadro 2): 1) Estágio 1 - Identificação, primeiro contato e início da aprendizagem, em que os relatores introduzem o tópico principal da narrativa, situando-o no tempo e no espaço de suas trajetórias (experiências) de aprendizagem; 2) Estágio 3 - Declaração do sucesso ou insucesso da aprendizagem; previsões de continuidade dos estudos na língua-alvo, no qual os relatores retomam o ponto central da narrativa e, ao mesmo tempo, avaliam seu desempenho de aprendizagem. Nesse estágio, há uma hibridização dos estágios de Avaliação e Coda, sinalizando algumas diferenças entre a proposta de Labov (1972) para análise de narrativas e a descrição genérica iniciada nesta pesquisa para narrativas de aprendizagem de línguas. Essa hibridização aponta para a necessidade de mais investigação desse tipo de narrativa, dada sua importância em pesquisas no campo do ensino de línguas que utilizam narrativas como registros de experiências de aprendizagem.

A análise das narrativas desta pesquisa, a partir da perspectiva de gêneros da Linguística Sistêmico-Funcional, também tentou preencher algumas das lacunas apresentadas por Pavlenko (2007) no tocante aos procedimentos de investigação narratológica, sobretudo no que se refere ao agrupamento de categorias semântico-discursivas para o entendimento dessas narrativas como representações de uma realidade específica e registros de avaliações acerca do processo de aprendizagem de uma língua estrangeira.

Além disso, no caso dos dados analisados neste estudo, o gênero narrativas de aprendizagem de línguas apresenta-se a partir de estágios de configuração de sua estrutura genérica, partindo de pressupostos apresentados por Martin (1984) e reelaborados por Eggins \& Martin (1997), Martin (2001) e Martin \& Rose (2003). A partir desses teóricos, as narrativas aqui investigadas podem ser inicialmente descritas em estágios constitutivos das práticas sociais de seus narradores, as quais são representadas discursivamente nesses estágios. No geral, os processos materiais, mentais e relacio- 
nais foram escolhidos pelos aprendizes de inglês como língua estrangeira para exprimirem, respectivamente, atividades, sensações e avaliações, e identificações, em momentos distintos, embora interligados, dos estágios constitutivos desse gênero. Nessa mesma linha de escolhas semânticodiscursivas, os temas textual, interpessoal e experiencial caracterizaram o fluxo discursivo das narrativas como registro de experiências vividas, mas com projeções de ações futuras, tipificando-as como um gênero diferenciado, se comparadas às narrativas investigadas por Labov (1972).

Este artigo, portanto, avança as discussões aventadas em RodriguesJúnior (2008) ao aplicar parte do modelo de Martin \& Rose (2003) às análises de narrativas de aprendizagem de línguas, cuja ênfase discursiva recai sobre a ideação associada aos elementos de avaliação e tematização, interpretados como recursos linguísticos que servem de registro às experiências de aprendizagem de seus narradores. Espera-se que desta pesquisa em andamento possam surgir investigações mais amplas dessas narrativas específicas, a partir da utilização integral do modelo de Martin \& Rose.

Recebido em agosto de 2009

Aprovado em outubro de 2009

E-mail: adail.sebastiao@gmail.com

\section{REFERÊNCIAS BIBLIOGRÁFICAS}

Аввотт, Н. Р. The Cambridge introduction to narrative. 2ed. Cambridge: Cambridge University Press, 2008.

BeLl, A. The language of news media. Oxford: Blackwell, 1991.

BELL, J. S. Narrative inquiry: more than just telling stories. TESOL Quarterly, v. 36, n. 2, p. 207-10, 2002.

CHASE, S. E. Narrative inquiry: multiple lenses, approaches, voices. In: Denzin, N. K. \& Y. S. Lincoln. Eds. The Sage handbook of qualitative research. 3 ed. Thousand Oaks, London e New Delhi: Sage, 2005. p. 651-679.

Clandinin, D. J. \& F. M. Connelly. Narrative inquiry: experience and story in qualitative research. San Francisco: Jossey-Bass Publishers, 2000.

EgGINS, S. An introduction to systemic functional linguistics. 2ed. London e New York, 2004.

EgGins, S. \& J. Martin. Genres and registers of discourse. In: van Dijk, T. Ed. Discourse as structure and process. Vol. I. London, Thousand Oaks, New Delhi: Sage, 1997. p. 230-256. 
EgGINs, S. \& D. Slade. Analysing casual conversation. London \& Washington: Cassel, 1997.

Fairclough, N. Analysing discourse: textual analysis for social research. London \& New York: Routledge, 2003.

GeE, J. P. A linguistic approach to narrative. Journal of Narrative and Life History, v. 1, n.1, p. 15-39, 1991.

Goffman, E. Frame analysis: an essay on the organization of experience. New York: Harper \& Row, 1974.

Gouveia, C. A. M. \& L. Barbara. Marked or unmarked that is NOT the question, the question is: Where's the Theme?. Ilha do Desterro, n. 46, p. 155-177, 2004.

Greimas, A. Sémantique structurale. Paris: Larousse, 1966.

Gumperz, J. Discourse strategies. Cambridge: Cambridge University Press, 1982.

Halliday, M. A. K. An introduction to functional grammar. London \& New York: Arnold, 1985. . An introduction to functional grammar. 2ed. London \& New York: Arnold, 1994.

. Explorations in the functions of language. London: Edward Arnold, 1973.

. Language as social semiotic: the social interpretation of language and meaning. London \& New York: Arnold, 1978.

Halliday, M. A. K. An Introduction to Functional Grammar. 3ed. Rev. C. M.

I. M. Matthiessen. London \& New York: Arnold, 2004.

Halliday, M. A. K. \& R. Hasan. (1985). Language, context, and text: aspects of language in a social-semiotic perspective. Geelong: Deakin University Press.

Heath, S. B. Ways with words: language, life, and work in communities and classrooms. Cambridge: Cambridge University Press, 1983.

Labov, W. Language in the inner city. Philadelphia: University of Pennsylvania Press, 1972.

LABOv, W. \& J. WALETZKY. Narrative analysis: oral versions of personal experience. Journal of Narrative and Life History, v. 7, n. especial, p. 3-38, 1997. (Originalmente publicado em 1967)

Martin, J. Language, register and genre. In: Christie, F. Ed. Children writing: a reader. Geelong, Vic.: Deakin University Press, 1984. p. 21-9.

Martin, J. Language, register and genre. In: Burns, A. \& C. Coffin. Eds. Analysing English in a global context: a reader. London, New York, 
Sydney: Routledge, The Open University, Macquirie University, 2001. p. 149-166.

Martin, J. \& D. Rose. Working with discourse: meaning beyond the clause. London \& New York: Continnuum, 2003.

Montgomery, M. Language, character and action: a linguistic approach to the analysis of character in a Hemingway short story. In: SINCLAIR, J. M., M. Hoey \& G. Fox. Eds. Techniques of description: spoken and written discourse. London \& New York, 1993. p. 127-42.

Pavlenko, A. Autobiographic narratives as data in Applied Linguistics. Applied Linguistics, v. 28, n. 2, p. 163-188, 2007.

. Narrative analysis. In: WeI, L. \& M. G. Moyer. Eds. The Blackwell guide to research methods in bilingualism and multilingualism. USA, UK, Australia: Blackwell Publishing, 2009. p. 311-25.

Propp, V. The morphology of the folktale. Austin, USA: University of Texas Press, 1968.

Riessman, C. K. Narrative analysis. Newbury Park, London \& New Delhi: Sage, 1993.

Rodrigues-Júnior, A. S. Ideação e avaliatividade em relatos de aprendizes de inglês como língua estrangeira. Revista Brasileira de Linguística Aplicada, v. 8, n. 2, p. 273-293, 2008.

. A representação de personagens gays na coleção de contos Stud e em sua tradução As aventuras de um garoto de programa. Tese de Doutorado. 255ff. Belo Horizonte: Faculdade de Letras da UFMG, 2006.

Schleppegrell, M. J. The language of schooling: a functional linguistics perspective. Mahawah, NJ e London: Lawrence Erlbaum Associates, Publishers, 2004.

Simpson, P. Language, ideology and point of view. London \& New York: Routledge, 1993.

Tannen, D. What's in a frame?. In: Freedle, R. Ed. New directions in discourse processing. Norwood, NJ: Ablex, 1979. p. 137-81.

Thompson, G. Introducing functional grammar. 2ed. London \& New York: Edward Arnold.

Toolan, M. Narrative: a critical linguistic introduction. 2ed. London \& New York: Routledge, 2001. 